\author{
Marika Świeszczak*
}

\title{
REKLAMY BANKOWE A ICH KONTEKST ETYCZNY
}

\begin{abstract}
Streszczenie: Banki $w$ działalności reklamowej powinny przestrzegać przepisów prawa, a także zasad etycznych. Kwestia występowania $w$ reklamach deficytów etycznych jest zagadnieniem szczególnie istotnym, gdyż rzutuje na pozytywny wizerunek banków i zaufanie do nich.

Celem niniejszego rozdziału jest umiejscowienie reklam bankowych $w$ kontekście etycznym, a także weryfikacja nieetyczności działalności reklamowej instytucji finansowych $w$ Polsce na podstawie analizy skarg wnoszonych przez konsumentów do Komisji Etyki Reklamy w latach 2007-2015 na reklamy określonych produktów poszczególnych banków.
\end{abstract}

Słowa kluczowe: reklamy bankowe, Komisja Etyki Reklamy, etyka, nośniki reklamy.

\section{WSTĘP}

U podstaw działalności każdego banku jest poznanie i zaspokojenie potrzeb klientów, co jest możliwe dzięki dopasowaniu swojej oferty do jego potrzeb. Reklamy pełnią ważną rolę w działalności instytucji finansowych, gdyż mają za zadanie pozyskanie klientów, poinformowanie ich o ofercie, a także przekonanie do dokonania zakupu. Należy przy tym wskazać, że szczególnie ważną sprawą jest takie konstruowanie komunikatów reklamowych, aby były one zgodne z przepisami prawa, ale również zasadami etyki. Co istotne, o ile określenie, czy dany przekaz jest zgodny lub niezgodny z prawem jest sprawą prostą, to decydowanie o jego etyczności niejednokrotnie stanowi poważne wyzwanie.

Celem tego rozdziału jest umiejscowienie reklam bankowych w kontekście etycznym, a także weryfikacja nieetyczności działalności reklamowej instytucji finansowych na podstawie analizy skarg wnoszonych przez konsumentów do Komisji Etyki Reklamy w latach 2007-2015 na reklamy określonych produktów poszczególnych banków.

\section{REKLAMY BANKOWE - PODSTAWOWE POJĘCIA}

Słowo reklama wywodzi się od łacińskiego reklamo, reclamare, oznaczającego „krzyczeć do kogoś, głośno sprzeciwiać się, odbrzmiewać echem, odbijać się, nawoływać" ". Za moment narodzin współczesnej reklamy uznaje się

\footnotetext{
* Dr Marika Świeszczak, Wydział Ekonomiczno-Socjologiczny, Uniwersytet Łódzki.

${ }^{1}$ Stownik łacińsko-polski, wg słownika H. Mengego i H. Kopii, oprac. K. Kumaniecki, PWN, Olsztyn 1982, s. 421-422.
} 
opublikowanie ogłoszenia informującego o sprzedaży bydła, które ukazało się $\mathrm{w}$ jednym $\mathrm{z}$ angielskich pism $\mathrm{w}$ XVIII $\mathrm{w}^{2}{ }^{2}$ Jednakże pierwsze definicje pojawiły się dopiero od lat 20. XX w., a za najstarszą uważa się formułę SLB (Stay, Look, Buy), wyznaczającą poszczególne etapy procesu reklamowania - „zwrócenie uwagi konsumenta na reklamowany towar i jej zatrzymanie; doprowadzenie do obejrzenia i poznania towaru przez konsumenta oraz sprowokowanie zakupu"3. Na podstawie tej definicji stworzono model AIDA (Attention, Interest, Desire, Action), który wyznaczył reklamie funkcję zwrócenia uwagi na produkt, wzbudzenia zainteresowania produktem, pobudzenia chęci posiadania produktu i wywołania pożądanego działania (zakup) ${ }^{4}$, zaś kolejnym krokiem było opracowanie modelu DIPADA (Definition, Identification, Proof, Acceptance, Desire, Action), sprowadzającego funkcję reklamy do oddziaływania na nabywcę w kierunku pożądanym przez nabywcę ${ }^{5}$ Na drodze tej ewolucji Amerykańskie Stowarzyszenie Marketingu stworzyło najbardziej precyzyjną definicję: „reklama jest każdą płatną formą nieosobistej prezentacji i popierania idei posiadania dóbr i usług przez ściśle określonego, zainteresowanego nadawcę. Reklama jest wiedzą i sztuką. Wiedza jest konieczna dla poznania prawidłowości związanej z pełnieniem przez reklamę roli marketingowej komunikacji z nabywcami oraz psychologicznych uwarunkowań - jej percepcji przez odbiorców. Sztuka reklamy to opisywanie i przedstawianie korzyści produktów dla nabywców i skłanianie do ich zakupu za pomocą nieosobowych środków przekazu"6. Powstałe na przestrzeni kolejnych lat definicje przedstawia tab. 1 .

Rynek reklamy wciąż się rozwija, zaś wieloaspektowość pojęcia sprawia, że jego jednoznaczne zdefiniowanie jest zadaniem trudnym. Przytoczone definicje pokazują, że w zależności od kontekstu można różnorodnie opisywać ten termin, dlatego też w pracy zostanie wykorzystana następująca definicja: „reklamą jest każda odpłatna, nieosobowa, zgodna z prawem i dobrymi obyczajami forma oddziaływania na odbiorców i mająca na celu skłonienie ich do określonego działania”.

${ }^{2}$ A. M. Dereń, E. Próchniak, Reklama a prawo. Poradnik dla przedsiębiorców, TNOiK, Bydgoszcz 1997, s. 9.

${ }^{3}$ Szerzej: Z. Foltyński (red.), Reklama w handlu zagranicznym, PWE, Poznań 1983.

${ }^{4}$ W. Budzyński, Reklama. Techniki skutecznej perswazji, Poltext, Warszawa 1999, s. 39.

${ }^{5} \mathrm{Ph}$. Kotler, Marketing, Management, Planning and Control, Prentice Hall, Englewood Cliffs 1980, s. 407; J. H. Chłopocki, Reklama - rozwój, pojęcia, metody, [w:] Materiały na II Kongres Reklamy Polskiej, Aida Media, Poznań 1993, s. 9-12.

${ }^{6}$ T. Sztucki, Encyklopedia marketingu, Wydawnictwo Placet, Warszawa 1998, s. 266. 
Tabela 1. Wybrane definicje pojęcia reklama

\begin{tabular}{|c|c|}
\hline Autor & Definicja \\
\hline 1 & 2 \\
\hline M. Barańska & $\begin{array}{l}\text { Jest to jedna } \mathrm{z} \text { form marketingowej prezentacji, zgodna z prawem } \\
\text { i dobrymi obyczajami, odpłatna, prowadzona w celu utrzymania bądź } \\
\text { zwiększenia popytu na towary lub usługi, wpływająca na decyzje } \\
\text { potencjalnych nabywców za pośrednictwem środków masowego } \\
\text { komunikowania i innych środków docierania w sposób zorganizowa- } \\
\text { ny w interesie reklamodawcy. }\end{array}$ \\
\hline W. Budzyński & $\begin{array}{l}\text { Każdy przekaz zmierzający do promocji sprzedaży lub innych form } \\
\text { korzystania z towarów czy usług, popierania określonych spraw i idei } \\
\text { albo osiągnięcia innego efektu zamierzonego przez reklamodawcę, } \\
\text { nadawany za opłatą lub inną formą wynagrodzenia. }\end{array}$ \\
\hline D. Bulmore & $\begin{array}{l}\text { Reklama jest jakimkolwiek płatnym przekazem mającym na celu } \\
\text { informowanie i/lub wpłynięcie na jednostkę lub grupę ludzi. }\end{array}$ \\
\hline $\begin{array}{l}\text { Europejska } \\
\text { Konwencja } \\
\text { o Telewizji } \\
\text { Ponadgranicznej }\end{array}$ & $\begin{array}{l}\text { Reklama oznacza wszelkie publiczne obwieszczenia, mające na celu } \\
\text { popieranie sprzedaży, zakupu lub wynajmu produktu lub usługi, } \\
\text { promocję idei czy sprawy lub spowodowanie innego skutku pożąda- } \\
\text { nego przez reklamującego, dla których celów udzielono reklamują- } \\
\text { cemu czasu transmisyjnego na zasadach odpłatności lub za inne po- } \\
\text { dobne wynagrodzenie. }\end{array}$ \\
\hline M. Golka & $\begin{array}{l}\text { Reklamą jest każdy płatny sposób nieosobistego prezentowania } \\
\text { i popierania zakupu towarów (usług, idei) przy pomocy określonych } \\
\text { środków, w określonych ramach prawnych i w określonych warun- } \\
\text { kach, wraz z podawaniem informacji o samych towarach, ich zale- } \\
\text { tach, ewentualnie cenie, miejscach i możliwościach realizacji zakupu. }\end{array}$ \\
\hline A. Grzegorczyk & $\begin{array}{l}\text { Reklama to płatna, bezpośrednia komunikacja (przez różne środki } \\
\text { przekazu) firm lub innych organizacji i jednostek, które są identyfi- } \\
\text { kowane z treścią przekazu lub mają nadzieję poinformować lub prze- } \\
\text { konać czytelników pewnej grupy odbiorców. Na codzienny użytek } \\
\text { reklama to jawny płatny przekaz o charakterze perswazyjnym poprzez } \\
\text { środki masowego przekazu. }\end{array}$ \\
\hline J. Kall & $\begin{array}{l}\text { O reklamie mówimy wówczas, gdy w sposób bezosobowy (bez udzia- } \\
\text { łu sprzedawcy) i za pieniądze (w przeciwieństwie do publicity) pre- } \\
\text { zentuje się produkt lub usługę. }\end{array}$ \\
\hline $\mathrm{Ph}$. Kotler & $\begin{array}{l}\text { Reklama jest publicznym oddziaływaniem perswazyjnym, zróżnico- } \\
\text { wanym i ekspansywnym. }\end{array}$ \\
\hline A. Kozłowska & $\begin{array}{l}\text { U podstaw przekazów reklamowych leżą potrzeby konsumentów, } \\
\text { które motywują ich do określonego zachowania. }\end{array}$ \\
\hline K. Laszczak & $\begin{array}{l}\text { Ciąg uporządkowanych sygnałów zmniejszających niepewność po- } \\
\text { tencjalnego nabywcy co do cech produktu i zwiększających atrakcyj- } \\
\text { ność produktu. Dzięki reklamie przywracany jest więc wewnętrzny } \\
\text { porządek, gdyż potencjalny nabywca, opierając się na informacji, } \\
\text { może kreować swoją własną, spójną wizję rzeczywistości. }\end{array}$ \\
\hline $\begin{array}{l}\text { Międzynarodowy } \\
\text { Kodeks Praktyki } \\
\text { Reklamowej }\end{array}$ & $\begin{array}{l}\text { Każda forma reklamy towarów i usług, niezależnie od użytego środka } \\
\text { łącznie z napisami reklamowymi na opakowaniach, etykietach i w miej- } \\
\text { scu sprzedaży. }\end{array}$ \\
\hline
\end{tabular}


Tabela 1 (cd.)

\begin{tabular}{|l|l|}
\hline \multicolumn{1}{|c|}{1} & \multicolumn{1}{|c|}{2} \\
\hline \hline $\begin{array}{l}\text { Międzynarodowy } \\
\text { Kodeks Reklamy }\end{array}$ & $\begin{array}{l}\text { Reklama obejmuje każdą formę prezentowania towarów i usług, } \\
\text { niezależnie od użytego środka, łącznie z napisami na opakowaniach, } \\
\text { etykietach i w miejscu sprzedaży. }\end{array}$ \\
\hline E. Nowińska & $\begin{array}{l}\text { Świadome działanie przedsiębiorcy zmierzające do promowania } \\
\text { towarów lub usług przez wskazanie na ich cechy w taki sposób, aby } \\
\text { wywołać lub wzmocnić określone potrzeby u klientów (konsumen- } \\
\text { tów). }\end{array}$ \\
\hline $\begin{array}{l}\text { Oddział } \\
\text { Międzynarodowego } \\
\text { Reklamy w Polsce }\end{array}$ & $\begin{array}{l}\text { Termin ,reklama” obejmuje wszystkie formy przekazywania informacji } \\
\text { o produktach, usługach lub instytucjach, niezależnie od użytego środka } \\
\text { przekazu i włączając w to reklamowe stwierdzenia na opakowaniach, } \\
\text { nalepkach i materiałach promocyjnych w punktach sprzedaży. }\end{array}$ \\
\hline Z. Roszkowski & $\begin{array}{l}\text { Płatna, bezosobowa forma prezentacji i poprawiania sprzedaży pro- } \\
\text { duktów. }\end{array}$ \\
\hline M. Sagan & $\begin{array}{l}\text { Każda wypowiedź, której celem jest chęć promocji towarów i usług, } \\
\text { niezależnie od użytego nośnika. }\end{array}$ \\
\hline T. Sztucki & $\begin{array}{l}\text { Płatna forma prezentacji czy promocji idei, produktu lub usługi. Re- } \\
\text { klama ma przede wszystkim budować w świadomości nabywcy obraz } \\
\text { i markę produktu poprzez zwielokrotnienie przekazu. }\end{array}$ \\
\hline $\begin{array}{l}\text { Ustawa } \\
\text { z 29 grudnia 1992 } r . \\
\text { o radiofonii } \text { i telewizji }\end{array}$ & $\begin{array}{l}\text { Każdy przekaz zmierzający do promocji sprzedaży albo innych } \\
\text { form korzystania z towarów lub usług, popierania określonych } \\
\text { spraw i idei albo do osiągnięcia innego efektu pożądanego przez } \\
\text { reklamodawcę, nadawany za opłatą lub inną formą wynagrodzenia. }\end{array}$ \\
\hline
\end{tabular}

Źródło: opracowanie własne na podstawie: M. Barańska, Reklama i jej ograniczenia. Standardy europejskie a prawo polskie, Poltext Sp. z o. o., Warszawa 2011, s. 24; W. Budzyński, Reklama. Techniki skutecznej perswazji, Poltext, Warszawa 1999, s. 12; D. Bulmore, Billboard, Wydawnictwo Naukowe PWN, Warszawa 2006; Europejska Konwencja o Telewizji Ponadgranicznej z 5 maja 1989 r., art.2, punkt f; M. Golka, Świat reklamy, Agencja badawczo-promocyjna ARTIA, Warszawa 1994, s. 13; A. M. Grzegorczyk, Retoryka w środowisku komunikacji rynkowej. Podręcznik dla studentów Wyższej Szkoły Promocji, Warszawa 2003, s. 28; J. Kall, Reklama, PWE, Warszawa 2000, s. 17; J. Grzywacz, Marketing $w$ działalności banku, Difin, Warszawa 2006, s. 124; A. Kozłowska, Reklama. Socjotechnika oddziaływania, Oficyna Wydawnicza Wyższej Szkoły Handlowej, Warszawa 2001, s. 41; M. Laszczak, Psychologia przekazu reklamowego, Wydawnictwo Profesjonalnej Szkoły Biznesu, Kraków 1998; R. Walczak, Prawne aspekty reklamy $w$ ustawodawstwie polskim, europejskim i międzynarodowym. Orzecznictwo, Polskie Wydawnictwo Prawnicze IURIS Sp. z o.o., Warszawa-Poznań 2001, s. 58; Międzynarodowy Kodeks Reklamy, 1991, art. 2, §1; E. Nowińska, M. du Vall, Komentarz do ustawy o zwalczaniu nieuczciwej konkurencji, LexisNexis, Warszawa 2001, s. 142; Oddział Międzynarodowego Stowarzyszenia Reklamy w Polsce, http://iaa.org.pl/o-reklamie/iaa-poleca.html [dostęp: 2.09.2014]; Z. Roszkowski, Marketing bankowy, Wydawnictwo WSE, Białystok 2002, s. 147; M. Sagan, Reklama żywności w świetle polskiego prawa, „Przegląd Prawa Handlowego” 1996, nr 5, s. 17; T. Sztucki, Encyklopedia marketingu, Wydawnictwo Placet, Warszawa 1998, s. 266; Ustawa z dnia 29 grudnia 1992 r. o radiofonii i telewizji, DzU 1993, nr 7, poz. 34, ze zm. 
Podstawową funkcją reklamy jest wywieranie wpływu na odbiorcę komunikatu w celu kreowania u niego określonych potrzeb. Jednakże reklamy, a zwłaszcza reklamy bankowe, pełnią także funkcję edukacyjną, polegającą na przekazywaniu potencjalnemu klientowi informacji o sytuacji na rynku, oddziaływaniu na potrzebę nabycia produktów lub usług o najwyższej jakości, odpowiadającym najwyższym standardom, itd. Zagadnienie to jest nierozerwalnie związane z zagadnieniami etyki w komunikatach reklamowych, które wymagają od nadawcy przekazu udzielenia pełnej informacji, tak żeby konsument dokonał świadomego wyboru.

Co istotne, w zależności od etapu działalności gospodarczej nadawcy reklam, zadania stojące przed przekazami reklamowymi są różne. Do podstawowych celów reklamy należą: ${ }^{7}$

- budowanie u klientów świadomości marki,

- kreowanie lojalności konsumentów wobec marki,

- edukowanie nabywców produktów/usług,

- konkurowanie z innymi podmiotami,

- kreowanie wizerunku przedsiębiorstwa.

Podmiot gospodarczy, który jest nowy na rynku, poprzez reklamę chce poinformować potencjalnych klientów o swoim istnieniu oraz oferowanych produktach/usługach, a także zapewnić sobie rozpoznawalność marki (logo, slogan reklamowy, misja). W sytuacji wprowadzania na rynek nowego asortymentu, reklama ma pomóc przedsiębiorstwu w poinformowaniu o tym konsumentów, rozpowszechnieniu informacji, przekonywaniu do nowości oraz pozyskiwaniu nowych klientów. Na etapie zwiększania sprzedaży dojrzałego produktu/usługi komunikaty reklamowe informują o korzyściach z określonego zakupu, przyciągają nowych nabywców oraz wzmacniają lojalność. W przypadku, gdy spada sprzedaż, a przedsiębiorstwo chce zapobiec tej sytuacji, reklamy pełnią następujące zadania:

- wzmocnienie lojalności klientów,

- informacja o korzyściach, zmianach, ulepszeniach w ofercie,

- ponowne pozyskanie nowych klientów,

- udzielenie informacji o ofercie, w tym także jako odpowiedź na akcję promocyjną konkurentów.

$\mathrm{Na}$ etapie walki z konkurencją, reklama ma za zadanie poinformować klientów o korzyściach z zakupu, ulepszenie asortymentu oraz wzmocnienie lojalności. Jeżeli podmiot gospodarczy chce uzasadnić wprowadzane w dotychczasowej ofercie zmiany, wówczas komunikat reklamowy ma wzmocnić lojalność klientów oraz poinformować ich o korzyściach wynikających z tych modyfikacji. W przypadku, gdy zmiany dotyczą miejsca sprzedaży (zmiana siedziby lub

${ }^{7}$ B. Kwarciak, Co trzeba wiedzieć o reklamie, Wydawnictwo Profesjonalnej Szkoły Biznesu, Kraków 1999, s. 36. 
otwarcie nowych punktów sprzedaży) reklama ma na celu poinformować o tym fakcie konsumentów oraz pozyskać nowych nabywców. Z kolei zmiana opinii na temat oferowanych produktów/usług, wprowadzana $\mathrm{w}$ celu rozpoczęcia sprzedaży na nowym rynku, ma za zadanie poinformowanie klientów o specyfikacji oferty, pokazanie korzyści z zakupu (zaspokojenie potrzeb) oraz przyciągnięcie nowych pośredników obsługujących dany rynek ${ }^{8}$.

\section{REKLAMA BANKÓW W MEDIACH}

Ze względu na rodzaj mediów wykorzystanych do budowy komunikatu mediów ${ }^{9}$ :

- prasowa - reklama umieszczona w prasie,

- telewizyjna - komunikat reklamowy emitowany za pomocą telewizji,

- radiowa - nośnikiem reklamy jest radio,

- kinowa - reklama jest emitowana w kinie,

- pocztowa (direct mail) - wykorzystywanie w procesie komunikowania poczty,

- zewnętrzna (outdoor) - reklama umieszczona na zewnątrz placówki, np. szyld, billboard, tablica reklamowa,

- internetowa - wykorzystywanym medium jest Internet.

Poszczególne rodzaje mediów mają określone implikacje dla reklam. Wybór prasy jako medium wiąże się z krótkim czasem życia tytułu prasowego, co w konsekwencji przekłada się na krótki czas ekspozycji komunikatu. Ponadto należy pamiętać, że czasopisma i gazety mają określoną grupę odbiorców, a ponadto czytelnicy koncentrują swoją uwagę poznawczą na innych treściach. Wadą reklam prasowych jest również to, że istnieje ryzyko przytłumienia reklamy przez inne, w tym także konkurencyjne. Jednak wybór tego medium wiąże się także z wieloma zaletami. Przede wszystkim jest to duża częstotliwość przekazu informacji oraz szeroki odbiór w prasie. Sam proces wydawniczy jest krótki, w związku z czym komunikat szybko trafia do odbiorców, którzy ponadto mogą wielokrotnie się z nim zapoznawać. Jest to także wygodna forma kontaktu z potencjalnymi klientami, gdyż stwarza możliwość przekazania precyzyjnej i stosunkowo obszernej informacji, a także dopasowywania oferty do warunków otoczenia $^{10}$.

Reklama telewizyjna charakteryzuje się dużą atrakcyjnością, dużą siłą oddziaływania na odbiorcę oraz dużym zasięgiem przestrzennym. Co istotne, wy-

\footnotetext{
${ }^{8}$ W. Budzyński, Sztuka skutecznej reklamy, „Marketing w Praktyce” 1996, nr 1, s. 43.

${ }^{9}$ A. Czubała, Podstawy marketingu, PWE, Warszawa 2012, s. 211.

${ }^{10} \mathrm{~J}$. Mikosz, Reklama prasowa - rodzaje i podrodzaje. Sposoby promocje prasy, „Folia Litteraria Polonica" 2011, nr 14, s. 54-55.
} 
korzystując to medium nadawca komunikatu może dokładnie przedstawić reklamowany produkt czy usługę i ich cechy charakterystyczne. Ze względu na dużą popularność telewizji wśród odbiorców, reklama łatwo trafia do odbiorców, a także można powiedzieć, że łatwo za jej pomocą kształtować popyt. Jednakże telewizja jako medium posiada także wady, jak choćby krótki czas emisji czy wysokie koszty produkcji i emisji. Co istotne, czas od momentu utworzenia do nadania komunikatu jest stosunkowo długi, co stwarza możliwości dla konkurencji oraz zagrożenie dezaktualizacją treści. Warto podkreślić ryzyko wystąpienia zakłóceń w percepcji reklamy, jakie może się pojawić ze względu na krótki czas emisji, a także negatywne nastawienie społeczeństwa do reklam telewizyjnych ${ }^{11}$.

W przypadku kina zasięg oddziaływania komunikatu jest znacznie mniejszy niż dla telewizji, a ponadto dociera wyłącznie do określonej grupy odbiorców (osoby młode i w średnim wieku), co powoduje, że nie każdy produkt czy usługa może być w ten sposób reklamowana. Czas emisji reklamy jest krótki, jednak czas tworzenia jest relatywnie długi, co rodzi podobne zagrożenia co przy reklamie telewizyjnej. Warto podkreślić wysokie koszty produkcji i emisji takiego komunikatu, a także możliwość wystąpienia zakłóceń w percepcji spotu ze względu na krótki czas jego emisji. Jednak należy podkreślić atrakcyjność takiego przekazu oraz dużą siłę oddziaływania na odbiorcę. Podobnie jak w przypadku reklam telewizyjnych, komunikaty wyświetlane w kinie cechują się stosunkowo dużym zasięgiem przestrzennym, możliwością wiernego odzwierciedlenia cech produktu czy usługi oraz wysoką zdolnością kształtowania popytu $^{12}$.

Reklama radiowa zapewnia prostotę i atrakcyjność przekazu. Komunikat przygotowuje się łatwo i szybko, zaś koszty emisji są stosunkowo niskie. Radio stwarza także możliwość dotarcia do określonej grupy klientów, co wiąże się również z relatywnie dużą selektywnością oddziaływania. Warto podkreślić także migawkowość i ulotność komunikatu, co powoduje trudność w zapamiętaniu informacji oraz powierzchowność przekazu. Ponadto zasięg oddziaływania jest mocno zróżnicowany, w konsekwencji czego konieczne jest określenie grupy odbiorców już na etapie tworzenia reklamy oraz weryfikacja, czy to medium pozwoli na dotarcie do nich ${ }^{13}$.

Reklama pocztowa cechuje się dużą siłą oddziaływania perswazyjnego dzięki indywidualizacji wyboru adresata i przekazu informacji. Konstruując taki przekaz mamy możliwość dotarcia do dokładnie określonej grupy odbiorców, zaś same koszty tego procesu są stosunkowo niskie. Komunikat pocztowy charakteryzuje się prywatnością oraz dużą wygodą odbioru (konsument może otwo-

${ }^{11}$ J. Kall, Reklama, PWE, Warszawa 1998, s. 89-90.

${ }^{12}$ A. Grzegorczyk, Reklama, Warszawa 2010, s. 92-93.

${ }^{13}$ R. Polak, I. Leonowicz-Bukała, S. Gawroński, Narzędzia współczesnej reklamy. Stosowanie i zapotrzebowanie, Wydawnictwo WSIiZ, Rzeszów 2010, s. 29-48. 
rzyć pocztę w dogodnym dla niego momencie), a ponadto istnieje możliwość fizycznego zaprezentowania produktu w postaci jego fizycznej próbki. Jednak przy dużym natężeniu reklamy pocztowej odbiorcy mają tendencję do zniechęcania się, zarówno do samego produktu czy usługi, jak i samej formy komunikacji, gdyż odbierają ją jako natarczywą ${ }^{14}$.

Reklama zewnętrzna nie pozwala na ocenę rzeczywistych efektów reklamy, a także cechuje się niewielką selektywnością ${ }^{15}$. Do jej zalet należą ${ }^{16}$ :

- powszechność i łatwość dotarcia do konsumenta,

- możliwość umieszczenia dłuższego tekstu,

- możliwość wielokrotnego kontaktu z komunikatem,

- ważna forma uzupełniająca kampanii, szczególnie w zakresie kształtowania świadomości marki,

- względnie stała forma reklamy,

- stosunkowo niski koszt.

Reklama internetowa różni się zasadniczo od reklamy tradycyjnej (wymienione wcześniej), co wynika przede wszystkim z odmienności Internetu jako medium. Jedną z cech odróżniających jest to, że Internet, biorąc pod uwage koszt dotarcia przekazu, stanowi relatywnie tani kanał komunikacji z indywidualnym odbiorcą. Co istotne, umożliwia on również komunikację dwukierunkową w czasie rzeczywistym, gdyż stwarza możliwość udzielenia odpowiedzi na przekaz lub zadania pytania do oferty. Należy także podkreślić, że to medium zapewnia największy, bo globalny, zasięg oddziaływania. Ponadto stwarza możliwość pozyskania nowego klienta w ciągu całej dobry, gdyż funkcjonuje 24 godziny. Ponadto Internet umożliwia dotarcie komunikatu do wybranych odbiorców z pominięciem pośredników, a także pozwala dostosować treść przekazu do oczekiwań indywidualnego odbiorcy i monitorować jego reakcje. Do istotnych cech tego medium należy również to, że wymaga ono zaangażowania odbiorcy, a także ułatwia pozyskiwanie i selekcję informacji, w tym również wymianę informacji z innymi użytkownikami. Jednakże nadmiar treści często powoduje, że użytkownicy pomijają reklamy oraz nie zapoznają się $\mathrm{z}$ treścią komunikatów ze względu na ich wszechobecność i nachalność. Medium to nie pozwala dotrzeć do odbiorców, którzy na co dzień nie korzystają z Internetu, np. osoby starsze ${ }^{17}$.

Wybór określonego medium zależy od potrzeb nadawcy komunikatu, należy przy tym pamiętać, że wiąże się on z określonymi konsekwencjami, związanymi ze specyfiką poszczególnych nośników reklamy.

${ }^{14}$ A. Kozłowski, Strategia reklamowa jako proces komunikowania się przedsiębiorstwa z rynkiem, PARP, Warszawa 2006, s. 6.

${ }^{15}$ D. Holder, Reklama prasowa, [w:] M. J. Thomas, Podręcznik marketingu, Wydawnictwo Naukowe PWN, Warszawa 1998, s. 570.

${ }^{16}$ T. Sztucki, Promocja. Sztuka pozyskiwania nabywców, Placet, Warszawa 1995, s. 22 i 66.

${ }^{17}$ A. Bajdak, Internet $w$ marketingu, PWE, Warszawa 2003. 


\section{ETYKA W REKLAMACH BANKOWYCH}

Etykę należy traktować jako filozoficzne studium moralnej wartości ludzkiego postępowania i zasad, które nim rządzą ${ }^{18}$, zaś postawy etyczne jako powszechnie przyjęte i akceptowalne standardy postępowania przedstawicieli wybranych zawodów oraz podmiotów gospodarczych ${ }^{19}$. W bardzo szerokim ujęciu etykę definiuje się poprzez pryzmat możliwości identyfikacji dobra i zła ${ }^{20}$ oraz prowadzonej działalności i problemów z nią związanych. ${ }^{21}$ Analizując zjawisko z innej perspektywy, etyka stanowi całokształt zasad i kodeksów postępowania przedsiębiorców ${ }^{22}$. Ogromne znaczenie odgrywa w tym podejściu specyfika relacji pomiędzy podmiotami gospodarczymi oraz ich interesariuszami, którzy oczekują, iż współpraca będzie kreowana w oparciu o normy i wartości etyczne ${ }^{23}$.

Działalność banków jest nierozerwalnie związana z pojawianiem się dylematów etycznych ${ }^{24}$, zaś niejednokrotnie granica pomiędzy zachowaniami etycznymi i nieetycznymi jest niewyraźna ${ }^{25}$. Etyka w bankowości koncentruje się wokół trzech obszarów ${ }^{26}$ :

- zasad etycznych transakcji dokonywanych na rynkach finansowych (reguły panujące na rynkach finansowych, np. każdy uczestnik powinien posiadać jednakowy dostęp do informacji),

- reguł budowania relacji z klientami (koncentracja na budowaniu długoterminowych relacji),

- dylematów osobistych osób zaangażowanych w dwa poprzednie obszary.

${ }^{18}$ B. Grimshaw, Ethical Issues and Agendas, „Facilities” 2001, vol. 19, s. 43.

${ }^{19}$ T. L. Wheelen, J. D. Hunger, Strategic Management and Business Policy, Prentice Hall, New Jersey 2002, s. 43.

20 Z. Rezaee, Corporate Governance Post-Sarbanes-Oxley: Regulations, Requirements, and Integrated Processes, John Wiley \& Sons, Hoboken 2007, s. 440.

${ }^{21}$ R. R. Sims, Ethics and Corporate Social Responsibility: Why Giants Fall, Greenwood Publishing Group, London 2003, s. 13.

${ }^{22}$ N. Gopalsamy, A Guide To Corporate Governance, New Age International, New Delhi 2006, s. 107.

${ }^{23}$ A. C. Ricardo, Business Environment, Pearson Education India, New Delhi 2011, s. 386.

${ }^{24}$ Szerzej na ten temat: G. Simmel, Filozofia pieniadza, Wydawnictwo Fundacji Humaniora, Poznań 1997; L. V. Ryan (red.), Etyka biznesu. Z klasyki wspótczesnej myśli amerykańskiej, Wydawnictwo „W drodze”, Poznań 1997; G. D. Chryssides, J. H. Kaler, Wprowadzenie do etyki biznesu, Wydawnictwo Naukowe PWN, Warszawa 2008; B. Klimczak, Etyka gospodarcza, Wydawnictwo Akademii Ekonomicznej we Wrocławiu, Wrocław 2007.

${ }^{25}$ Ch. P. Kindleberger, Szaleństwo, panika, krach. Historia kryzysów finansowych, Wydawnictwo WIG-Press, Warszawa 1999, s. 130.

${ }^{26}$ W. Gasparski (red.), Uczciwość w świecie finansów, Wyższa Szkoła Przedsiębiorczości i Zarządzania im. L. Koźmińskiego, Warszawa 2004, s. 23-24; W. Szpringer, Kredyt konsumencki $i$ upadłość konsumencka na rynku ustug finansowych UE, ABC Dom Wydawniczy, Warszawa 2005, s. 119. 
Pierwsza kategoria dotyczy ogólnych reguł panujących na rynkach finansowych. Zgodnie z nimi każdy uczestnik powinien dysponować taką samą informacją o podmiotach i warunkach zawierania transakcji, zaś sposób dokonywania zakupów powinien być taki sam dla wszystkich. Na szczególną uwagę zasługuje informacja, która powinna być jak najpełniejsza, do czego powinni dążyć wszyscy uczestnicy rynków finansowych. Należy przy tym podkreślić, że zasady etyczne tych transakcji (czyli w szczególności zakaz sprzeniewierzania i manipulacji, konieczność przestrzegania reguł uczciwej konkurencji, przestrzeganie przepisów antymonopolowych, itp.) są regulowane prawem, jednakże pomimo określenia, jakie czyny są niedozwolone, co jakiś czas pojawiają się sytuacje ich naruszeń.

W odniesieniu do reklam bankowych instytucje finansowe sformułowały katalog $\operatorname{zasad}^{27}$ :

- reklamy powinny rzetelnie informować klientów o prowadzonej działalności,

- banki, informując o świadczonych usługach i ich warunkach, powinny zapewnić klientowi pełną i rzetelną informację, w tym o możliwościach uzyskania dodatkowych korzyści oraz o kosztach i ryzykach związanych z poszczególnymi oferowanymi usługami,

- ocena usług oferowanych przez banki należy do klientów, a w związku z tym banki nie powinny:

- odnosić się w reklamach do ofert innych banków ani kreować negatywnych wizerunków konkurentów,

- poddawać w swoich reklamach w wątpliwość solidności innych banków ani oceniać ich działalności,

- finansować dokonywanych przez prasę i instytucje niebankowe porównań ofert bankowych w celu zapewnienia wiarygodności i obiektywizmu własnych ofert.

Przytoczone zasady pokazują, że etyka jest obszarem szczególnie ważnym w bankach, gdyż są one postrzegane jako instytucje zaufania publicznego, a więc te cechy mają dla nich pierwszorzędne znaczenie. W odniesieniu do działalności reklamowej można wyróżnić potencjalne kwestie etyczne w obrębie poszczególnych instrumentów ${ }^{28}$ :

- decyzje związane $\mathrm{z}$ produktem - dotyczą polityki wprowadzania i wycofywania produktów,

- decyzje związane z działaniami promocyjnymi - stosowanie reklamy niezgodnej z przepisami prawa i zasadami etycznymi,

${ }^{27}$ Zasady Dobrej Praktyki Bankowej, rozdz. IV, Związek Banków Polskich 2001.

${ }^{28}$ J. P. Peter, J. H. Donelly, A Preface to Marketing Management, Richard D. Irwin, Burr Ridge 2000; W. M. Pride, O. C. Ferrell, Marketing: Concepts and Strategies, Houghton Mifflin 2010; Ph. Kotler, G. Armstrong, I. Saunders, V. Wong, Marketing. Podręcznik europejski, PWE, Warszawa 2002. 
- decyzje cenowe - dotyczą zbyt wysokich cen produktów,

- decyzje związane z działaniami dystrybucyjnymi - dotyczą sposobów docierania z produktami do klientów.

W przypadku działalności reklamowej banków kwestie etyczne występują szczególnie często w dwóch obszarach: promocji i cenie, co związane jest z oparciem reklam na zasadzie przekonywania, czyli nakłaniania konsumenta do podjęcia określonego działania lub przyjęcia określonego poglądu. Należy przy tym wskazać, że dyskusyjne etycznie jest zarówno samo wywieranie wpływu na odbiorcę, jak i jego forma i użyte do tego celu narzędzia. Takie podejście należy potraktować jako manipulację klientem, zaś jej rozmiar jest uzależniony od samego celu komunikatu (można mówić o szkodliwym oddziaływaniu reklamy, często niezgodnym z prawem lub dobrymi obyczajami, bądź też oddziaływaniem na decyzje konsumenta, ale w granicach określonych zasadami prawa i etyki).

U podstaw skuteczności reklam bankowych znajdują się potrzeby konsumentów, rozumiane jako, ,poczucie braku czegoś wynikające $\mathrm{z}$ dostrzegania różnicy między istniejącym stanem rzeczy a stanem pożądanym"29 i motywujące go do określonego zachowania ${ }^{30}$. Zatem skuteczność komunikatów jest tym wyższa, im bardziej podkreśli różnicę pomiędzy stanem pożądanym a stanem rzeczywistym. Należy przy tym wskazać, że stopień oddziaływania reklamy na decyzje zakupowe klientów jest uwarunkowany szeregiem czynników, zarówno zewnętrznych (socjologiczne, kulturowe, demograficzne, ekonomiczne i związane z użytymi przez podmiot instrumentami marketingowymi i poziomem ich perswazyjności), jak i wewnętrznych (związanych z osobowością człowieka) ${ }^{31}$.

Oddziaływanie na decyzje konsumentów jest realizowane przy wykorzystaniu technik perswazji, których celem jest przyciągnięcie uwagi odbiorcy, budowanie odpowiedniego nastawienia emocjonalnego, tworzenie zaufania do treści przekazu oraz zwiększanie zaangażowania konsumenta w odbiór przekazu ${ }^{32}$.

\section{NIEETYCZNE ASPEKTY REKLAM BANKOWYCH}

Zagadnienie nieetycznych aspektów reklam bankowych należy rozważać w kontekście występowania deficytów etycznych (wszelkie naruszenia zasad etycznych przez reklamy bankowe), powodujących negatywne konsekwencje w ludzkiej świadomości. Istotnym problemem jest określenie poziomu etyczności działań, przy czym stosunkowo prosto odróżnić reklamy etyczne od nieetycznych, jednakże w przypadku tych pierwszych mamy do czynienia z różnym

\footnotetext{
${ }^{29}$ L. Grabski, Zachowania nabywców, PWE, Warszawa 1998, s. 179.

${ }^{30}$ A. Kozłowska, Reklama. Techniki perswazyjne, SGH, Warszawa 2011, s. 41.

${ }^{31}$ R. Nowacki, Reklama, Difin, Warszawa 2005, s. 210.

${ }^{32}$ A. Dejnaka, Strategia reklamy marki, produktów i usług, OnePress, Gliwice 2005, s. 14.
} 
poziomem przestrzegania zasad etycznych (zob. schemat 1). Podmioty, które ograniczają się tylko do przestrzegania przepisów prawa, nie mogą być postrzegane tak samo jak podmioty, które dbają również o poszanowanie wartości i tradycji społecznych.
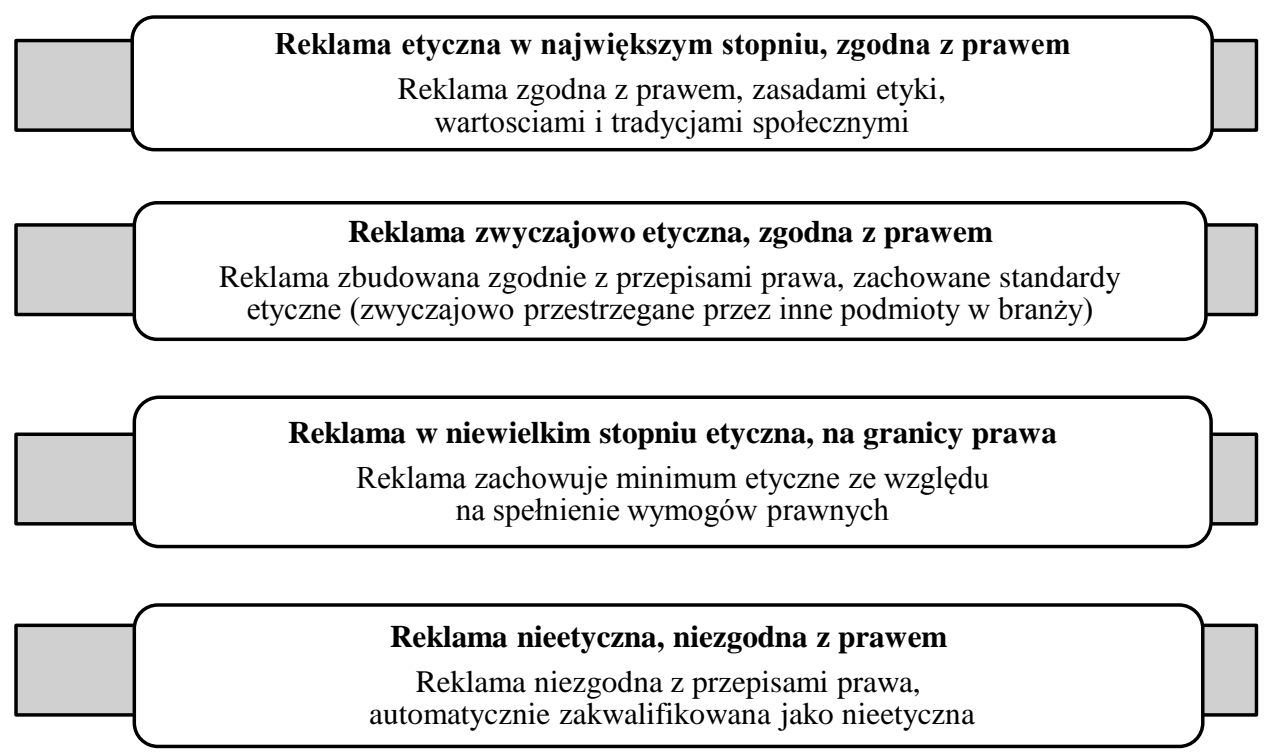

Schemat 1. Poziomy etyczności reklam

Źródło: opracowanie własne na podstawie: S. Hollensen, Marketing Management. A Relationship Approach, FT Prentice Hall, Harlow 2003, s. 712.

Kontynuując rozważania na temat etyczności reklam należy wskazać, że ich emisja jest regulowana przez prawo, w szczególności przez:

- Kodeks Postepowania w Dziedzinie Reklamy ${ }^{33}$, przygotowanego na podstawie Międzynarodowego Kodeksu Etycznego Reklamy. Jego podstawowe zasady odnoszą się do:

- zgodnej z prawem i normami obyczajowymi, uczciwej i zgodnej z prawdą działalności reklamowej,

- przygotowanej z należytym poczuciem odpowiedzialności i przestrzegającej ogólnie przyjętych i uznawanych reguł uczciwej konkurencji reklamy,

- nie podważania społecznego zaufania do działalności reklamowej.

${ }^{33}$ Międzynarodowe Stowarzyszenie Reklamy (IAA), http://iaa.org.pl/o-reklamie/kodeksy/kodeks-postepowania-w-dziedzinie-reklamy.html [dostęp: 30.11.2015]. 
- Zasady Etyki w Reklamie Politycznej ${ }^{34}$ - zasady zabraniają m.in. używania treści naruszających normy obyczajowe, nadużywania zaufania odbiorcy i wyników badań, zachęcania do przemocy i dyskryminacji, a także dyskredytowania innych polityków, firm czy ugrupowań politycznych.

- Kodeks Etyki Reklamy ${ }^{35}$, zawierający zbiór zasad etycznych i dobrych obyczajów, które powinny być przestrzegane w reklamach.

- Kodeks Dobrych Praktyk Członków Stowarzyszenia Agencji Reklamowych (SAR) przyjęty przez członków tej organizacji w 2005 r.

- Deklaracja Przeciwdziałania Ukrytej Reklamie podpisana przez Izbę Wydawców Prasy, PKPP Lewiatan, Polskie Radio SA, Polskie Stowarzyszenie Public Relations, Stowarzyszenie Agencji Reklamowych, Stowarzyszenie Dziennikarzy Polskich, Syndykat Dziennikarzy Polskich, Związek Firm Public Relations, Telewizję Polską SA, Związek Pracodawców Prywatnych Mediów oraz Związek Zawodowy Dziennikarzy Radia i Telewizji.

$\mathrm{Z}$ punktu widzenia etyki oraz wpływu reklam na decyzje klientów za najważniejszą regulację należy uznać Ustawe $z$ dnia 16 stycznia $1993 r$ r. o zwalczaniu nieuczciwej konkurencji. W świetle tego prawa zakazane są następujące rodzaje przekazów ${ }^{36}$ :

- sprzeczne z przepisami prawa lub dobrymi obyczajami oraz uchybiające godności człowieka,

- wprowadzające konsumenta w błąd, oddziałując w ten sposób na decyzje klientów, do których w szczególności należą:

- reklamy kłamliwe - zawierające fałszywe informacje,

- reklamy oszukańcze - dwuznaczność przekazu jest konsekwencją tendencyjnego przedstawiania produktów,

- reklamy niepełne - pomijające ważne informacje o produkcie,

- reklamy naśladownicze - będące kopią innych reklam,

- oczywiste - podkreślające cechy charakterystyczne danego produktu,

- przesadne - nadmiernie eksponujące cechy produktu,

- naruszające cudze oznaczenie handlowe - wykorzystujące w komunikacie cechy wyróżniające na rynku inny podmiot,

- nierzeczowe - bazujące wyłącznie na uczuciach i emocjach odbiorcy komunikatu,

- ukryte - podświadomie sugerujące zakup określonego produktu,

\footnotetext{
${ }^{34}$ Międzynarodowe Stowarzyszenie Reklamy (IAA), http://iaa.org.pl/o-reklamie/kodeksy/zasady-etyki-w-reklamie-politycznej.html [dostęp: 30.11.2015].

${ }^{35}$ Międzynarodowe Stowarzyszenie Reklamy (IAA), http://iaa.org.pl/o-reklamie/kodeksy/dobrowolny-kodeks-postepowania-w-zakresie-reklamy-i-promocji-piwa.html [dostęp: 30.11.2015].

${ }^{36}$ Ustawa z dnia 16 stycznia 1993 r. o zwalczaniu nieuczciwej konkurencji, DzU 1993, nr 47 poz. 211, ze zm.
} 
- uciążliwe - naruszające prywatność konsumenta,

- porównawcze - zawierające porównanie produktów i umożliwiające w ten sposób identyfikację konkurenta.

$\mathrm{Z}$ punktu widzenia etyki przestrzeganie wyłącznie prawa jest niewystarczające, konieczne jest także przestrzeganie zasad etycznych. W Kodeksie Etyki Bankowej oraz Kodeksie Etyki Reklamy można znaleźć zalecenie, zgodnie z którym reklama „powinna być rzetelna, nie może wprowadzać w błąd oraz cechować się poszanowaniem powszechnie obowiązujących przepisów prawa, zasad uczciwego obrotu oraz dobrych obyczajów"37. Stąd też można powiedzieć, że Kodeks Etyki Bankowej i Kodeks Etyki Reklamy stanowią najważniejszy wyznacznik zgodności reklam z zasadami etyki i dobrymi obyczajami.

Co istotne, najbardziej dyskusyjnym obszarem reklam jest ich wykorzystanie do manipulowania uczuciami, emocjami i zachowaniami nabywców, w wyniku zastosowania następujących zabiegów:

- wykorzystania w określonym celu wizerunku człowieka, przekazującego informacje o produkcie lub usłudze i zachęcające do jego zakupu, np. wizerunek kobiety jako gospodyni domowej, businesswoman, obiektu pożądania, gwiazdy, a wizerunku mężczyzny jako eksperta $\mathrm{w}$ danej dziedzinie, głowy rodziny, macho lub gwiazdora znanego z życia publicznego ${ }^{38}$,

- wykorzystania stereotypów, m.in. kobiety jako obiektu seksualnego, osoby rozrzutnej, a mężczyzny jako człowieka zarozumiałego lub nieporadnego ${ }^{39}$,

- zastosowania prowokacji (np. użycie motywu śmierci, symboli religijnych i wizerunku znanych osób) ${ }^{40}$,

- odwołania do emocji (np. radość, satysfakcja, duma, szczęście, lęk, zdenerwowanie $)^{41}$,

- kreowania potrzeby poprzez ich wizualizację ${ }^{42}$,

- odwołania się do nieomylności ogółu społeczeństwa ${ }^{43}$.

Konsumenci mają prawo złożyć skargę do Komisji Etyki Reklamy, jeśli uznają oni, ze dany komunikat jest sprzeczny z zasadami etyki. Na przestrzeni lat 2007-2015 złożono 60 skarg na reklamy bankowe (w roku 2014 r. nie

37 Kodeks Etyki Reklamy, http://www.radareklamy.org/kodeks-etyki-reklamy.htm [dostęp 26.02.2014]; Kodeks Etyki Bankowej, http://www.bph.pl/repo/bph/zasa-dy_dobrej_praktyki_bankowej.pdf [dostęp: 26.02.2014].

${ }^{38}$ A. Kozłowska, Reklama. Techniki..., s. 370-399.

${ }^{39}$ R. Nowacki, op. cit., s. 234-235.

${ }^{40}$ N. K. Pope, K. E. Voges, M. R. Brown, The Effect of Provocation in the Form of Mild Erotica on Attitude to the Ad and Corporate Image: Differences between Cause-Related and Product-Based Advertising, ,Journal of Advertising” 2004, Spring, s. 1.

${ }^{41}$ A. Pratkanis, E. Aronson, Wiek propagandy, PWN, Warszawa 2004, s. 163.

${ }^{42} \mathrm{Ph}$. G. Zimbardo, M. R. Leippe, Psychologia zmiany postaw $i$ wplywu społecznego, Zysk i S-ka, Poznań 2004, s. 215.

${ }^{43}$ R. Cialdini, Wywieranie wptywu na ludzi. Teoria i praktyka, GWP Gdańskie Wydawnictwo Psychologiczne, Gdańsk 2011, s. 113-114. 
wniesiono żadnych zastrzeżeń), z czego 22 przekazy KER uznała za naruszające etykę. Co istotne, można zauważyć wzrost świadomości klientów, którzy na przestrzeni lat w coraz większym zakresie składali zażalenia na komunikaty banków (tab. 2).

Tabela 2. Zestawienie liczby skarg wniesionych przez konsumentów do Komisji Etyki Reklamy na przekazy reklamowe banków w latach 2007-2015 oraz decyzje KER

\begin{tabular}{|c|c|c|c|}
\hline \multirow{2}{*}{ Rok } & \multirow{2}{*}{ Liczba skarg } & \multicolumn{2}{|c|}{ Decyzje komisji etyki reklamy } \\
\cline { 3 - 4 } & & Oddalone & Podtrzymane \\
\hline \hline 2007 & 2 & 2 & 0 \\
\hline 2008 & 7 & 6 & 4 \\
\hline 2009 & 7 & 3 & 1 \\
\hline 2010 & 5 & 4 & 2 \\
\hline 2011 & 5 & 3 & 5 \\
\hline 2012 & 9 & 4 & 7 \\
\hline 2013 & 14 & 7 & 2 \\
\hline 2015 & 11 & 9 & \\
\hline
\end{tabular}

Źródło: opracowanie własne na podstawie: https://www.radareklamy.pl/uchwaly [dostęp: 30.11.2015].

Tabela 3 przedstawia zestawienie skarg wniesionych przez konsumentów do Komisji Etyki Reklamy na przekazy reklamowe poszczególnych banków oraz decyzje KER. Jak można zauważyć, w latach 2007-2015 najwięcej skarg do Komisji Etyki Reklamy wpłynęło w sprawie reklam banków: mBank SA (9) i Alior Bank SA (8), jednakże korygując tę liczbę o decyzje oddalające, to najgorzej w klasyfikacji wypada Sygma Banque Société Anonyme SA (6) i Alior Bank SA (4).

Najwięcej skarg konsumentów wniesionych do Komisji Etyki Reklamy w latach 2007-2015 dotyczyła wprowadzania w błąd (22), faktu, że reklama nie była prowadzona w poczuciu odpowiedzialności społecznej oraz zgodnie $\mathrm{z}$ dobrymi obyczajami (21) oraz tego, że komunikat nie mieści się w ramach przyjętych norm etycznych (19) - tab. 4.

Analizując dane zawarte w tab. 5 można zauważyć, że najwięcej skarg wniesionych do Komisji Etyki Reklamy w latach 2007-2015 dotyczyło reklam telewizyjnych (28) i internetowych (14) banków. W badanym okresie konsumenci nie podważali etyczności reklam prasowych, kinowych i pocztowych.

Najwięcej skarg konsumentów wniesionych do Komisji Etyki Reklamy w latach 2007-2015 dotyczyło kredytów (13) i kont osobistych (12), zaś najmniej kont emerytalnych (2) - tab. 6. Zaobserwowane zjawisko ma związek z faktem, ze najwięcej emitowanych reklam dotyczy właśnie tych produktów jako sposobów zaspokojenia podstawowych potrzeb społeczeństwa. 
Tabela 3. Zestawienie liczby skarg wniesionych przez konsumentów do Komisji Etyki Reklamy na przekazy reklamowe poszczególnych banków w latach 2007-2015 oraz decyzje KER

\begin{tabular}{|c|c|c|c|c|}
\hline \multirow{2}{*}{ Bank } & \multirow{2}{*}{ Lata } & \multirow{2}{*}{ Liczba skarg } & \multicolumn{2}{|c|}{ Decyzje komisji etyki reklamy } \\
\hline & & & Oddalone & Podtrzymane \\
\hline \multirow{4}{*}{ BZ WBK SA } & 2007 & 1 & 1 & 0 \\
\hline & 2011 & 1 & 1 & 0 \\
\hline & 2013 & 1 & 1 & 0 \\
\hline & 2015 & 1 & 1 & 0 \\
\hline \multirow{3}{*}{ Idea Bank SA } & 2007 & 1 & 1 & 0 \\
\hline & 2012 & 2 & 0 & 2 \\
\hline & 2013 & 2 & 2 & 0 \\
\hline \multirow{5}{*}{ ING Bank Śląski SA } & 2008 & 2 & 1 & 1 \\
\hline & 2009 & 1 & 1 & 0 \\
\hline & 2010 & 2 & 1 & 1 \\
\hline & 2012 & 1 & 1 & 0 \\
\hline & 2013 & 1 & 0 & 1 \\
\hline \multirow{6}{*}{$\begin{array}{c}\text { mBank SA } \\
\text { (dawniej BRE Bank SA) }\end{array}$} & 2008 & 2 & 2 & 0 \\
\hline & 2010 & 2 & 2 & 0 \\
\hline & 2011 & 1 & 0 & 1 \\
\hline & 2012 & 2 & 0 & 2 \\
\hline & 2013 & 1 & 1 & 0 \\
\hline & 2015 & 1 & 1 & 0 \\
\hline \multirow{2}{*}{ EFG Eurobank Ergasis SA } & 2008 & 2 & 2 & 0 \\
\hline & 2009 & 1 & 1 & \\
\hline \multirow{3}{*}{ Bank BPH SA } & 2008 & 1 & 1 & 0 \\
\hline & 2009 & 1 & 1 & 0 \\
\hline & 2014 & 1 & 1 & 0 \\
\hline \multirow{5}{*}{ Alior Bank SA } & 2009 & 2 & 0 & 2 \\
\hline & 2011 & 1 & 0 & 1 \\
\hline & 2012 & 2 & 1 & 1 \\
\hline & 2013 & 2 & 2 & 0 \\
\hline & 2015 & 1 & 1 & 0 \\
\hline Dominet Bank SA & 2009 & 1 & 0 & 1 \\
\hline \multirow{3}{*}{$\begin{array}{c}\text { Getin Noble Bank SA } \\
\text { (wcześniej Getin Bank SA) }\end{array}$} & 2009 & 1 & 0 & 1 \\
\hline & 2012 & 1 & 1 & 0 \\
\hline & 2015 & 1 & 1 & 0 \\
\hline Bank Pocztowy SA & 2010 & 1 & 1 & 0 \\
\hline PKO BP SA & 2013 & 2 & 2 & 0 \\
\hline \multirow{2}{*}{$\begin{array}{c}\text { BNP Paribas } \\
\text { Bank Polska SA }\end{array}$} & 2012 & 2 & 2 & 0 \\
\hline & 2015 & 3 & 3 & 0 \\
\hline $\begin{array}{c}\text { Sygma Banque Société } \\
\text { Anonyme SA } \\
\end{array}$ & 2013 & 6 & 0 & 6 \\
\hline Deutsche Bank Polska SA & 2015 & 2 & 0 & 2 \\
\hline Bank BGŻ SA & 2015 & 1 & 1 & 0 \\
\hline
\end{tabular}

Źródło: jak do tab. 2. 
Tabela 4. Zestawienie kategorii skarg wniesionych przez konsumentów do Komisji Etyki Reklamy na przekazy reklamowe banków w latach 2007-2015

\begin{tabular}{|c|c|c|c|c|c|c|c|c|}
\hline \multirow[b]{2}{*}{ Rok } & \multicolumn{8}{|c|}{ Zarzut } \\
\hline & 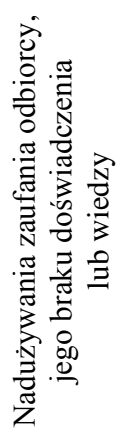 & 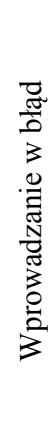 & 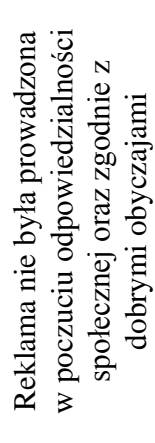 & 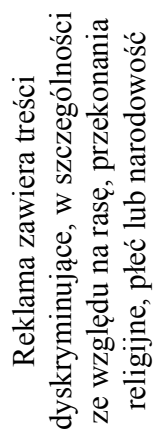 & 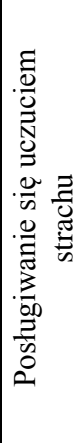 & 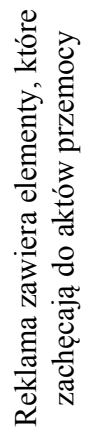 & 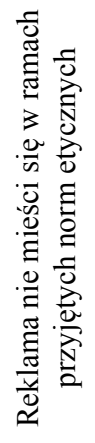 & 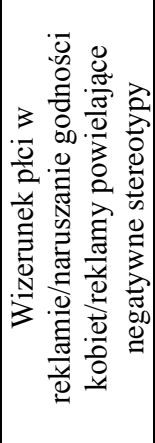 \\
\hline 2007 & 2 & 2 & & & & & & \\
\hline 2008 & & & & & & & 7 & 1 \\
\hline 2009 & 1 & 3 & & & & & & 4 \\
\hline 2010 & & & 3 & 1 & & & 4 & \\
\hline 2011 & & 1 & 3 & & & & 5 & \\
\hline 2012 & & 2 & 7 & 3 & & & 4 & \\
\hline 2013 & 6 & 9 & 3 & 2 & 1 & & & \\
\hline 2015 & 5 & 5 & 5 & & & 1 & 2 & \\
\hline SUMA & 14 & 22 & 21 & 6 & 1 & 1 & 19 & 5 \\
\hline
\end{tabular}

Źródło: jak do tab. 2.

Tabela 5. Zestawienie skarg wniesionych przez konsumentów do Komisji Etyki Reklamy na przekazy reklamowe banków w latach 2007-2015 według rodzaju nośnika

(bez uwzględnienia w ogólnej liczbie skarg odwołań od uchwał)

\begin{tabular}{|c|c|c|c|c|c|c|c|}
\hline \multirow[b]{2}{*}{ Rok } & \multicolumn{7}{|c|}{ Liczba skarg } \\
\hline & 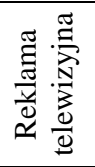 & 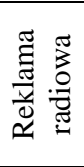 & 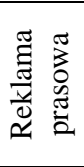 & 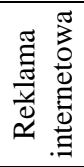 & 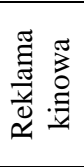 & 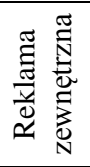 & 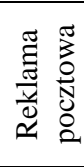 \\
\hline \multicolumn{8}{|l|}{2007} \\
\hline 2008 & 4 & 2 & & & & 1 & \\
\hline 2009 & 3 & & & 2 & & 2 & \\
\hline 2010 & 5 & & & & & & \\
\hline 2011 & 3 & & & & & 2 & \\
\hline 2012 & 4 & 1 & & 3 & & 1 & \\
\hline 2013 & 5 & & & 6 & & & \\
\hline 2015 & 5 & 1 & & 3 & & 1 & \\
\hline SUMA & 28 & 3 & 0 & 14 & 0 & 6 & 0 \\
\hline
\end{tabular}

Źródło: jak do tab. 2. 
Tabela 6. Zestawienie skarg wniesionych przez konsumentów do Komisji Etyki Reklamy na przekazy reklamowe banków w latach 2007-2015 według przedmiotu skargi (bez uwzględnienia w ogólnej liczbie skarg odwołań od uchwał)

\begin{tabular}{|c|c|c|c|c|c|c|c|c|}
\hline \multirow[b]{2}{*}{ Rok } & \multicolumn{8}{|c|}{ Liczba skarg } \\
\hline & 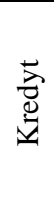 & 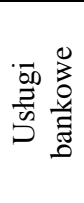 & 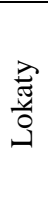 & 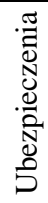 & 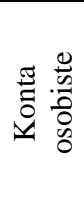 & 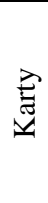 & $\begin{array}{l}\frac{\bar{y}}{N} \\
\text { D. } \\
0 \\
0\end{array}$ & 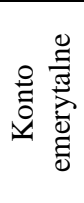 \\
\hline 2007 & & & & & & & & \\
\hline 2008 & 1 & & 2 & 2 & 2 & & & \\
\hline 2009 & 1 & & 4 & & 2 & & & \\
\hline 2010 & 1 & 2 & & 1 & 1 & & & \\
\hline 2011 & 1 & & & 1 & 2 & & 1 & \\
\hline 2012 & & 3 & & & 2 & & 1 & 2 \\
\hline 2013 & 4 & & & 1 & 1 & 4 & 1 & \\
\hline 2015 & 5 & 1 & & & 2 & 1 & 1 & \\
\hline SUMA & 13 & $\overline{c 6}$ & $\bar{~} 6$ & 5 & 12 & 5 & 4 & 2 \\
\hline
\end{tabular}

Źródło: jak do tab. 2.

\section{PODSUMOWANIE}

Banki są zobligowane do prowadzenia działalności (w tym także reklamowej) $\mathrm{w}$ granicach określonych przepisami prawa, ale również zasadami etyki, zawartymi w licznych kodeksach i ustawach. Instytucje finansowe mają do wyboru różne nośniki komunikatów reklamowych, zaś ich decyzje zdeterminowane są wieloma czynnikami, m.in. atrakcyjnością przekazu, zasięgiem odbioru czy kosztem emisji. Należy przy tym wskazać, że generalnie rośnie świadomość w zakresie etyki nie tylko banków, które podejmują szereg działań w tym obszarze, ale również klientów.

Kolejnym istotnym wnioskiem z przeprowadzonej analizy jest to, że wybór nośników reklam o największym zasięgu działania (jak Internet i telewizja) wiąże się z dotarciem do dużej liczby odbiorców, ale również ryzykiem wzbudzania u nich wątpliwości w zakresie przestrzegania zasad etyki. Co istotne, konsumenci dostrzegają różne aspekty, w których wystąpiły lub mogły wystąpić deficyty etyczne, przy czym najwięcej skarg dotyczyło produktów bankowych związanych $\mathrm{z}$ zaspokojeniem podstawowych potrzeb konsumentów- kredytów i kont osobistych. Optymizm budzi fakt, że do Komisji Etyki Reklamy nie zgłoszono zastrzeżeń co do etyczności reklam wielu banków, np. Pekao SA, Millennium SA czy też Raiffeisen Bank Polska SA, a co do wielu (np. Bank Pocztowy SA czy PKO BP SA) nie wnoszono skarg od dłuższego czasu, co może świadczyć o wysiłkach podejmowanych przez instytucje finansowe w zakresie przestrzegania w coraz większym stopniu zasad etycznych. 


\section{BIBLIOGRAFIA}

Bajdak A., Internet $w$ marketingu, PWE, Warszawa 2003.

Barańska M., Reklama i jej ograniczenia. Standardy europejskie a prawo polskie, Poltext sp. z o. o., Warszawa 2011.

Budzyński W., Reklama. Techniki skutecznej perswazji, Poltext, Warszawa 1999.

Budzyński W., Sztuka skutecznej reklamy, „Marketing w Praktyce” 1996, nr 1.

Bulmore D., Billboard, Wydawnictwo Naukowe PWN, Warszawa 2006.

Chłopocki J. H., Reklama - rozwój, pojęcia, metody, [w:] Materiały na II Kongres Reklamy Polskiej, Aida Media, Poznań 1993.

Chryssides G. D., Kaler J. H., Wprowadzenie do etyki biznesu, Wydawnictwo Naukowe PWN, Warszawa 2008.

Cialdini R., Wywieranie wplywu na ludzi. Teoria i praktyka, GWP Gdańskie Wydawnictwo Psychologiczne, Gdańsk 2011.

Czubała A., Podstawy marketingu, PWE, Warszawa 2012.

Dejnaka A., Strategia reklamy marki, produktów i ustug, OnePress, Gliwice 2005.

Dereń A. M., Próchniak E., Reklama a prawo. Poradnik dla przedsiębiorców, TNOiK, Bydgoszcz 1997.

Europejska Konwencja o Telewizji Ponadgranicznej z 5 maja 1989 r.

Foltyński Z. (red.), Reklama w handlu zagranicznym, PWE, Poznań 1983.

Gasparski W. (red.), Uczciwość w świecie finansów, Wyższa Szkoła Przedsiębiorczości i Zarządzania im. L. Koźmińskiego, Warszawa 2004.

Golka M., Świat reklamy, Agencja badawczo-promocyjna ARTIA, Warszawa 1994.

Gopalsamy N., A Guide To Corporate Governance, New Age International, New Delhi 2006.

Grabski L., Zachowania nabywców, PWE, Warszawa 1998.

Grimshaw B., Ethical Issues and Agendas, „Facilities” 2001, vol. 19.

Grzegorczyk A., Reklama, Warszawa 2010.

Grzegorczyk A. M., Retoryka w środowisku komunikacji rynkowej. Podręcznik dla studentów Wyższej Szkoły Promocji, Warszawa 2003.

Grzywacz J., Marketing w działalności banku, Difin, Warszawa 2006.

Holder D., Reklama prasowa, [w:] M. J. Thomas, Podręcznik marketingu, Wydawnictwo Naukowe PWN, Warszawa 1998.

Hollensen S., Marketing Management. A Relationship Approach, FT Prentice Hall, Harlow 2003.

Kall J., Reklama, PWE, Warszawa 1998.

Kall J., Reklama, PWE, Warszawa 2000.

Kindleberger Ch. P., Szaleństwo, panika, krach. Historia kryzysów finansowych, Wydawnictwo WIG-Press, Warszawa 1999.

Klimczak B., Etyka gospodarcza, Wydawnictwo Akademii Ekonomicznej we Wrocławiu, Wrocław 2007.

Kodeks Etyki Bankowej, http://www.bph.pl/repo/bph/zasady_dobrej_praktyki_bankowej.pdf.

Kodeks Etyki Reklamy, http://www.radareklamy.org/kodeks-etyki-reklamy.htm.

Kotler Ph., Armstrong G., Saunders I., Wong V., Marketing. Podręcznik europejski, PWE, Warszawa 2002.

Kotler Ph., Marketing, Management, Planning and Control, Prentice Hall, Englewood Cliffs 1980.

Kozłowska A., Reklama. Socjotechnika oddziaływania, Oficyna Wydawnicza Wyższej Szkoły Handlowej, Warszawa 2001.

Kozłowska A., Reklama. Techniki perswazyjne, SGH, Warszawa 2011.

Kozłowski A., Strategia reklamowa jako proces komunikowania się przedsiębiorstwa z rynkiem, PARP, Warszawa 2006. 
Kwarciak B., Co trzeba wiedzieć o reklamie, Wydawnictwo Profesjonalnej Szkoły Biznesu, Kraków 1999.

Laszczak M., Psychologia przekazu reklamowego, Wydawnictwo Profesjonalnej Szkoły Biznesu, Kraków 1998.

Międzynarodowe Stowarzyszenie Reklamy (IAA), http://iaa.org.pl/o-reklamie/kodeksy/dobrowolny-kodeks-postepowania-w-zakresie-reklamy-i-promocji-piwa.html.

Międzynarodowe Stowarzyszenie Reklamy (IAA), http://iaa.org.pl/o-reklamie/kodeksy/kodekspostepowania-w-dziedzinie-reklamy.html.

Międzynarodowe Stowarzyszenie Reklamy (IAA), http://iaa.org.pl/o-reklamie/kodeksy/zasadyetyki-w-reklamie-politycznej.html.

Międzynarodowy Kodeks Reklamy, 1991.

Mikosz J., Reklama prasowa - rodzaje i podrodzaje. Sposoby promocje prasy, „Folia Litteraria Polonica" 2011, nr 14.

Nowacki R., Promocja w zarządzaniu marketingowym przedsiębiorstwem, [w:] A. Olejniczuk-Merta (red.), Zarządzanie marketingowe matym i średnim przedsiębiorstwem, Difin, Warszawa 1999.

Nowacki R., Reklama, Difin, Warszawa 2005.

Nowińska E., du Vall M., Komentarz do ustawy o zwalczaniu nieuczciwej konkurencji, LexisNexis, Warszawa 2001.

Oddział Międzynarodowego Stowarzyszenia Reklamy w Polsce, http://iaa.org.pl/o-reklamie/iaapoleca.html.

Peter J. P., Donelly J. H., A Preface to Marketing Management, Richard D. Irwin, Burr Ridge 2000.

Polak R., Leonowicz-Bukała I., Gawroński S., Narzędzia współczesnej reklamy. Stosowanie i zapotrzebowanie, Wydawnictwo WSIiZ, Rzeszów 2010.

Pope N. K., Voges K. E., Brown M. R., The Effect of Provocation in the Form of Mild Erotica on Attitude to the Ad and Corporate Image: Differences between Cause-Related and Product-Based Advertising, ,Journal of Advertising” 2004, spring.

Pratkanis A., Aronson E., Wiek propagandy, PWN, Warszawa 2004.

Pride W. M., Ferrell O. C., Marketing: Concepts and Strategies, Houghton Mifflin 2010.

Rezaee Z., Corporate Governance Post-Sarbanes-Oxley: Regulations, Requirements, and Integrated Processes, John Wiley \& Sons, Hoboken 2007.

Ricardo A. C., Business Environment, Pearson Education India, New Delhi 2011.

Roszkowski Z., Marketing bankowy, Wydawnictwo WSE, Białystok 2002.

Ryan L. V. (red.), Etyka biznesu. Z klasyki współczesnej myśli amerykańskiej, Wydawnictwo „W drodze”, Poznań 1997.

Sagan M., Reklama żywności w świetle polskiego prawa, „Przegląd Prawa Handlowego” 1996, nr 5.

Simmel G., Filozofia pieniądza, Wydawnictwo Fundacji Humaniora, Poznań 1997.

Sims R. R., Ethics and Corporate Social Responsibility: Why Giants Fall, Greenwood Publishing Group, London 2003.

Słownik łacińsko-polski, wg słownika H. Mengego i H. Kopii, oprac. K. Kumaniecki, Wydawnictwo Naukowe PWN, Olsztyn 1982.

Szpringer W., Kredyt konsumencki $i$ upadtość konsumencka na rynku ustug finansowych UE, ABC Dom Wydawniczy, Warszawa 2005.

Sztucki T., Encyklopedia marketingu, Wydawnictwo Placet, Warszawa 1998.

Sztucki T., Promocja. Sztuka pozyskiwania nabywców, Placet, Warszawa 1995.

Ustawa z dnia 29 grudnia 1992 r. o radiofonii i telewizji, DzU 1993, nr 7, poz. 34, ze zm.

Ustawa z dnia 16 stycznia 1993 r. o zwalczaniu nieuczciwej konkurencji, DzU 1993, nr 47, poz. 211, ze zm. 
Walczak R., Prawne aspekty reklamy $w$ ustawodawstwie polskim, europejskim i międzynarodowym. Orzecznictwo, Polskie Wydawnictwo Prawnicze IURIS sp. z o.o., Warszawa-Poznań 2001.

Wheelen T. L., Hunger J. D., Strategic Management and Business Policy, Prentice Hall, New Jersey 2002.

Zasady Dobrej Praktyki Bankowej, Związek Banków Polskich, 2001.

Zimbardo Ph. G., Leippe M. R., Psychologia zmiany postaw $i$ wpływu społecznego, Zysk i S-ka, Poznań 2004.

https://www.radareklamy.pl/uchwaly

\title{
BANKS' ADVERTS AND THEIR CONTEXT OF ETHICS
}

\begin{abstract}
Banks in their advertising must comply with the law and ethical principles. The prevalence of ethics' deficits in advertising is an issue of particular importance, since affects the positive image of banks and trust them.

The aim of this paper is to place advertising in the context of ethical banking. as well as verification of ethical deficits in banks advertising activities on the basis of consumer complaints about the advertising of certain products of individual banks to the Committee of Advertising Ethics in the years 2007-2015.
\end{abstract}

Keywords: bank advertising, Committee of Advertising Ethics, ethics, media advertising. 